\title{
Konsumsi Makanan Siap Saji sebagai Faktor Dominan Terjadinya Dismenore pada Remaja
}

\author{
Ida Kusumawati ${ }^{1}$ Umi Aniroh $^{2}$ \\ 1,2 Program Studi S1 Keperawatan \\ Universitas Ngudi Waluyo \\ Email : kusumaida820@gmail.com
}

\begin{abstract}
ABSTRAK
Dismenore atau nyeri menstruasi merupakan salah satu masalah yang sering dikeluhkan remaja. Tujuan penelitian ini untuk mengetahui faktor paling dominan yang berhubungan dengan kejadian dismenore pada remaja. Jenis penelitian ini adalah penelitian observasional analitik dengan desain cross sectional. Sampel penelitian sebanyak 108 orang yang diambil dengan cara purposive sampling. Instrumen penelitian yang digunakan adalah kuesioner. Analisis data menggunakan chi-square dan regresi logistik. Hasil penelitian menunjukkan umur responden berkisar antara 13-17 tahun. Sebagian besar remaja 86 (79,6\%) tidak melakukan olahraga dengan teratur, sebagian besar remaja mengalami stres ringan sebanyak 58 orang $(53,7 \%)$, remaja sering mengkonsumsi makanan cepat saji sebanyak 76 orang $(70,4 \%)$ dan remaja mengalami kejadian dismenore sebanyak 81 orang $(75,0 \%)$. Ada hubungan antara kebiasaan olahraga dengan kejadian dismenore dengan $p=0,168 \leq \alpha(0,05)$, ada hubungan antara tingkat stres dengan kejadian dismenore dengan $p=0,070 \leq \alpha(0,05)$, ada hubungan antara konsumsi makanan cepat saji dengan kejadian dismenore dengan $p=0,001 \leq \alpha(0,05)$. Hasil akhir didapatkan yang paling berhubungan dengan kejadian dismenore adalah konsumsi makanan cepat saji. Saran bagi remaja putri lebih memperluas pengetahuan tentang dismenore agar saat mengalami kejadian dismenore dapat mengatasinya.
\end{abstract}

\section{Kata Kunci : Kebiasaan Olahraga, Tingkat Stres, Konsumsi Cepat Saji, Dismenore}

\begin{abstract}
The Consumption of Fast Food as a Dominan Factor to Occurring Dysmenorrhea of the Adolescent

Dysmenorrhea or menstrual pain is one of problems that is often complained adolescent. The purpose of the insulation is to know the most dominant factor related to the incident of dysmenore in adolescent. This type of research is an analytical observational research with cross sectional design. Sample research of 108 people taken by purposive sampling. The research instruments used are questionnaires. Analysis using Chi-square and logistic regression. Results show the average age of respondents was 13-17 years old. Most adolescent 86 (79.6\%) aren't do exercise regularly the majority of teenagers experience mild stress as much as 58 people (53.7\%), adolescent often consume fast food as many as 76 people (70.4\%) and adolescents experienced a dysmenore occurrence of 81 people (75.0\%). Results gained that there is a relationship between sports habits and dysmenore events with Pearson chi-square $p=0,168 \leq \alpha(0.05)$, there is a link between stress levels with a dysmenore occurrence with Pearson chi-square $p=$ $0,070 \leq \alpha(0.05)$, there is a connection between fast-consumption with a dysmenore
\end{abstract}


event with Pearson chi-square $p=0,000 \leq \alpha(0.05)$. The final result obtained that affect the incidence of dysmenore is the consumption of fast food. Advice for the adolescent further expands the knowledge of dysmenrhea so that when experiencing dysmenore events can overcome it.

\section{Keywords : Sports Habits, Stress Levels, Fast Food Consumption, Dysmenore}

\section{PENDAHULUAN}

Menurut WHO masa remaja adalah peralihan dari masa kanakkanak menuju masa dewasa, dimana pada masa itu terjadi pertumbuhan yang pesat termasuk fungsi reproduksi sehingga

mempengaruhi terjadinya perubahanperubahan perkembangan, baik fisik, mental, maupun peran sosial. Masa remaja merupakan salah satu tahap perkembangan dalam rentang kehidupan manusia. Pada tahap ini remaja akan mengalami suatu perkembangan fisik, seksual dan psikososial sebagai ciri dalam masa pubertas.

Salah satu tanda seorang wanita memasuki masa pubertas adalah mengalami menstruasi. Menstruasi merupakan keluarnya lapisan endometrium yang menyertai ovum yang tidak dibuahi dari saluran reproduksi berupa cairan yaitu darah. Salah satu gangguan kesehatan reproduksi yang terkait dengan menstruasi adalah dismenorea. Disminore ini menyebabkan rasa nyeri pada perut bagian bawah, yangmenyebar menjalar ke punggung bagian bawah dan tungkai. Rasa nyeri mulai timbul sesaat sebelum atau selama menstruasi (Manan, 2013).

Penelitian terdahulu yang dilakukan oleh Sirait ( 2014), di SMA Negeri 2 Medan dengan 128 responden, menunjukkan derajat kesakitan desminore $79,1 \%$ dismenore ringan, 8,2\% dismenore sedang dan $12,7 \%$ dismenore berat. Dari hasil penelitian menunjukkan terdapat hubungan yang bermakna antara kebiasaan olahraga dengan kejadian dismenore $(\mathrm{p}=0,040)$. Namun Penelitian yang dilakukan Pundati et al ( 2016), tentang Faktorfaktor yang Berhubungan dengan Kejadian Dismenore pada Mahasiswa Semester VIII Universitas Jendral Sudirman Purwokerto menyatakan bahwa tidak ada hubungan antara kebiasaan oleh raga dengan kejadian dismenore.

Penelitian yang dilakukan oleh Indahwati, Muftiana, \& Purwaningroom (2017), di SMP N 1 Ponorogo terkait hubungan konsumsi fast food dengan dismenore hasil penelitian menunjukkan bahwa 27 (42.9\%) responden sering mengonsumsi fast food dan mengalami dismenore. Hasil penelitian tersebut menunjukkan ada hubungan mengonsumsi makanan cepat saji (fast food) dengan kejadian dismenore.

Saputri (2011) melakukan penelitian pada siswi SMK Negeri 1 Karanganyar mendapatkan hasil, bahwa terdapat hubungan signifikan antara stres dengan kejadian dismenorea. Hal ini berbeda dengan penelitian yang dilakukan oleh yang judul hubungan antara tingkat stres, keaktifan olahraga dengan kejadian dismenore pada Mahasiswi Prodi S1 Keperawatan Stikes Dehasen Bengkulu justru mendapatkan hasil bahwa tidak ada hubungan antara stres dengan kejadian dismenorea.

Berdasarkan atas penelitianpenelitian tersebut, pertanyaan dalam 
penelitian ini adalah faktor apakah yang paling dominan, yang berhubungan dengan kejadian dismenore pada remaja?

Jenis penelitian ini adalah penelitian observasional analitik, dengan desain cross sectional. Penelitian ini dilakukan di MTs Assalafi Susukan Kabupaten Semarang pada bulan Februari 2020. Sampel penelitian sejumlah 108 siswi. Teknik pengambilan sampel yang digunakan adalah purposive sampling dengan kriteria siswi yang telah mengalami menstruasi dan bersedia menjadi responden

\section{HASIL DAN PEMBAHASAN}

Tabel 1.Distribusi Frekuensi

Karakteristik Responden BerdasarkanUmur

\begin{tabular}{ccc}
\hline Umur & Frekuensi & $\begin{array}{c}\text { Persentase } \\
(\boldsymbol{\%})\end{array}$ \\
\hline $7-12$ & 10 & 9,3 \\
tahun & & \\
$13-17$ & 98 & 90,7 \\
Tahun & & \\
\hline Jumlah & 108 & 100,0 \\
\hline
\end{tabular}

Berdasarkan tabel 1 di atas dapat di lihat bahwa frekuensi terbanyak responden berdasarkan umur pada direntan usia 13-17 tahun sebanyak 98 responden $(90,7 \%)$.

Tabel 2. Distribusi Frekuensi Responden Berdasarkan Kebiasaan Olahraga

\begin{tabular}{ccc}
\hline Kebiasaa & Frekuen & Persenta \\
n & si & se $(\%)$ \\
Olahrag & & \\
a & &
\end{tabular}

\begin{tabular}{ccc} 
a & & 48,1 \\
$\begin{array}{l}\text { Tidak } \\
\text { Rutin } \\
\text { Rutin }\end{array}$ & 52 & 51,9 \\
\hline Jumlah & 108 & 100,0 \\
\hline \multicolumn{4}{c}{ Berdasarkan } & tabel & 2 & dapat \\
diketahui bahwa & sebagian & besar
\end{tabular}

responden memiliki kebiasaan olahraga yang rutin, yaitu sejumlah 56 responden $(51,9 \%)$. Dengan jenis olahraga seperti senam, lari-lari, joging, bersepeda. Sebagian besar olahraga yang dilakukan responden dilakukan di rumah. Responden yang melakukan olahraga tidak rutin sebanyak 52 responden $(48,1 \%)$, melakukan oleh raga hanya dilakukan sekali seminggu saat pelajaran olehraga di sekolah.Salah satu cara yang efektif untuk mencegah dismenore adalah melakukan aktivitas olahraga. Olahraga secara teratur seperti berjalan kaki, jogging, berlari, bersepeda, renang atas senam aerobik dapat memperbaiki kesehatan dan menjaga siklus menstruasi agar teratur. Hal ini sesuai dengan penelitian Ramadhani (2014) bahwa berdasarkan uji Chi Square diperoleh nilai $p=0,00001$ dan disimpulkan ada hubungan yang signifikan antara kebiasaan olahraga dengan kejadian dismenore.

Tabel 3.Distribusi Frekuensi

Responden Berdasarkan Tingkat Stres

\begin{tabular}{ccc}
\hline $\begin{array}{l}\text { Tingka } \\
\text { t Stres }\end{array}$ & $\begin{array}{c}\text { Frekuens } \\
\text { i }\end{array}$ & $\begin{array}{c}\text { Persentas } \\
\text { e (\%) }\end{array}$ \\
\hline Ringan & 58 & 53,7 \\
Sedang & 50 & 46,3 \\
\hline Jumlah & 108 & 100,0 \\
\hline
\end{tabular}

Berdasarkan tabel 3 dapat diketahui bahwa sebagian besar responden mengalami stres ringan sejumlah 58 responden $(53,7 \%)$. Hal ini sejalan dengan penelitian Yunitasari dkk.( 2017) yang menyatakan bahwa tingkat stres pada siswi kelas VIII SMP N 3 Sragi yaitu stres ringan sebesar 10,4\% dan stres sedang sebesar $89,6 \%$ dengan hasil akhir nilai $p$-value 0,247 , sebagian besar siswi mengalami stres sedang 
karena banyaknya tuntutan dari sekolah maupun dari rumah yang membuat siswi menjadi emosional, kurang menerima keadaan dan sering marah-marah dengan teman.

Tabel 4.Distribusi Frekuensi

Responden Berdasarkan Konsumsi Fast Food

\begin{tabular}{ccc}
\hline $\begin{array}{c}\text { Konsum } \\
\text { si } \text { Fast } \\
\text { Food }\end{array}$ & $\begin{array}{c}\text { Frekuen } \\
\text { si }\end{array}$ & $\begin{array}{c}\text { Persenta } \\
\text { se }(\boldsymbol{\%})\end{array}$ \\
\hline Jarang & 32 & 29,6 \\
Sering & 76 & 70,4 \\
\hline Jumlah & 108 & 100,0 \\
\hline
\end{tabular}

Berdasarkan tabel 4 dapat diketahui bahwa sebagian besar responden sering mengkonsumsi makanan cepat saji yang yaitu sejumlah 76 responden $(70,4 \%)$. Nilsen (2008) menyatakan bahwa $69 \%$ masyarakat Indonesia mengonsumsi makanan cepat saji dan untuk golongan pelajar di Indonesia mengonsumsi fast food sebesar $83 \%$.

Hasil penelitian ini sejalan dengan penelitian Astuti (2014) yang menunjukkan bahwa 53 reponden yang terbanyak mengonsumsi fast food kategori sering sebanyak 42 responden (79.25\%) dan 11 responden dalam kategori jarang sebesar $(20.75 \%)$.

Tabel 5. Distribusi Frekuensi

Responden Berdasarkan Kejadian Dismenore

\begin{tabular}{ccc}
\hline $\begin{array}{c}\text { Kejadian } \\
\text { Dismeno } \\
\text { re }\end{array}$ & $\begin{array}{c}\text { Frekuen } \\
\text { si }\end{array}$ & $\begin{array}{c}\text { Persenta } \\
\text { se }(\%)\end{array}$ \\
\hline $\begin{array}{c}\text { Dismenor } \\
\text { e }\end{array}$ & 81 & 75,0 \\
Tida & 27 & 25,0 \\
$\begin{array}{c}\text { Dismenor } \\
\text { e }\end{array}$ & & \\
\hline Jumlah & 108 & 100,0 \\
\hline
\end{tabular}

$\begin{array}{ccc}\text { Berdasarkan tabel } & 5 \\ \text { menunjukkan sebagian } & \text { besar }\end{array}$ responden mengalami dismenore sejumlah $81(75,0 \%)$. Hal ini sesuai dengan hasil penelitian Sirait (2014) di SMA Negeri 2 Medan, dengan menggunakan desain cross sectional menunjukkan bahwa responden yang mengalami dismenore lebih banyak dibandingkan dengan responden yang tidak mengalami dismenore yaitu $81,3 \%$ siswi.

Hasil penelitian ini selaras dengan penelitian yang dilakukan oleh Gustina, (2015) dengan responden 148 siswi, hasil penelitian menunjukkan bahwa responden yang mengalami dismenore yaitu sebanyak 127 siswi (85,8\%), sedangkan yang tidak mengalami dismenore yaitu sebanyak 21 siswi (14,2\%).

Berdasarkan hasil penelitian Saguni, Madianung \& Masi (2013) kejadian dismenore didapatkan bahwa responden yang mengalami dismenore menunjukan persentase terbesar yaitu 121 responden $(91,7 \%)$.

Hal ini menggambarkan bahwa remaja putri di SMA Kristen I Tomohon yang sudah menstruasi umumnya mengalami dismenore.
Tabel 6. Hubungan Kebiasaan

Olahraga dengan Kejadian Dismenore

\begin{tabular}{lccc}
\hline Keb & Kejadian & Total & $p$ - \\
iasa & Dismenore & & $v a$
\end{tabular}




\begin{tabular}{|c|c|c|c|c|c|c|c|}
\hline \multirow[t]{2}{*}{$\begin{array}{c}\text { an } \\
\text { Ola } \\
\text { hra } \\
\text { ga }\end{array}$} & \multicolumn{2}{|c|}{$\begin{array}{l}\text { Dism } \\
\text { enore }\end{array}$} & \multicolumn{2}{|c|}{$\begin{array}{c}\text { Tida } \\
\mathbf{k} \\
\text { Dism } \\
\text { enore }\end{array}$} & & & \multirow[t]{2}{*}{$\begin{array}{l}l u \\
e\end{array}$} \\
\hline & $\mathbf{N}$ & $\%$ & n & $\%$ & $\mathbf{N}$ & $\%$ & \\
\hline Tida & 2 & 4 & 3 & 5 & 5 & 1 & \\
\hline $\mathrm{k}$ & 2 & 2 & 0 & 7 & 2 & 0 & 0 \\
\hline Ruti & & , & & , & & 0 & 0 \\
\hline $\mathrm{n}$ & & 3 & & 7 & & & 0 \\
\hline Ruti & 4 & 8 & 1 & 1 & 5 & 1 & 1 \\
\hline $\mathrm{n}$ & 6 & 2 & 0 & 7 & 6 & 0 & \\
\hline & & ' & & 9 & & 0 & \\
\hline Tota & 6 & 6 & 4 & 3 & 1 & 1 & \\
\hline 1 & 8 & 3, & 0 & 7, & 0 & 0 & \\
\hline & & 0 & & 0 & 8 & 0 & \\
\hline
\end{tabular}

Hasil tabulasi silang sebagaimana ditunjukkan pada tabel 6 ditemukan bahwa responden yang melakukan olahraga rutin sebagian besar mengalami dismenore, sejumlah 46 responden $(82,1 \%)$. Sedangkan siswi yang tidak rutin melakukan olahraga sebagian besar tidak mengalami kejadian dismenore, sejumlah 30 responden $(57,7 \%)$.

Hasil uji Chi Square (Continuity Correction) diperoleh pvalue 0,001. ( $<\alpha 0,05)$, maka disimpulkan bahwa ada hubungan secara signifikan antara kebiasaan olahraga dengan kejadian dismenore pada remaja di MTs Assalafi Susukan. Dari hasil uji ini juga diperoleh nilai Odds Ratio sebesar 0,159 . Ini menunjukkan bahwa responden yang memiliki kebiasaan olahraga secara rutin maka 0,159 kali tidak mengalami dismenore dibandingkan dengan responden yang memiliki kebiasaan olahraga tidak rutin.

Seorang remaja wanita yang melakukan aktivitas olahraga secara rutin dan teratur sebanyak dua atau lebih tiap seminggu memiliki kecenderungan yang lebih kecil untuk menderita dismenore dibandingkan dengan remaja yang melakukan olahraga yang tidak teratur atau kurang dari 2 kali dalam satu minggu menurut Bahri, Afriwardi, \& Yusrawati ( 2015).

Dari hasil penelitian yang sudah dilakukan terdapat kesenjagan antara kebiasaan olahraga dengan kejadian dismenore, yaitu didalam teori menjelaskan bahwa olahraga secara rutin akan mengurangi rasa dismenore pada remaja namun dalam penelitian ini terdapat 46 responden $(82,1 \%)$ mengalami dismenore walaupun sudah melakukan olahraga secara rutin, hal ini dimungkinkan olahraga yang dilakukan kurang intensitas dan kesungguhannya.

Hal ini sejalan dengan hasil penelitian Fajaryati (2012), yang dilakukan di SMP N 2 Mirit Kebumen menyatakan bahwa Hasil uji statistik dengan menggunakan uji chi square diperoleh nilai $\mathrm{p}$ value $=0,019$ artinya terdapat hubungan yang bermakna antara kebiasaan olahraga dengan kejadian dismenore. Rasio Prevalensi kejadian dismenore siswi yang jarang berolahraga dan yang yang sering berolahraga adalah 1,215 (1,004 $1,473)$. Siswi yang jarang berolahraga memiliki kemungkinan risiko 1,2 kali lebih besar mengalami dismenore dari pada siswi yang sering berolahraga (Sophia,2013), namun berbeda dengan penelitian Husnida dan Sutianingsih (2015) tentang Hubungan antara Status Gizi dan Oleh Raga dengan Kejadian Dismenore pada Mahasiswi Jurusan Kebidanan Rangkasbitung Tahun 2015 menunjukkan tidak terdapat hubungan yang bermakna antara kebiasaan olahraga dengan kejadian dismenore.

Tabel 7. Hubungan Tingkat Stres 
dengan Kejadian Dismenore

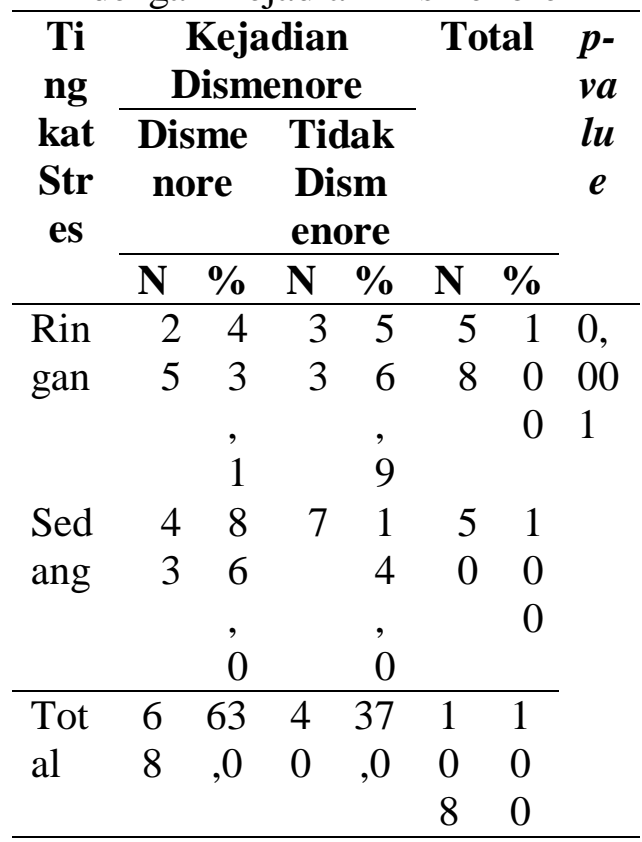

Pada tabel 7 menunjukkan bahwa responden dengan tingkat stres ringan lebih banyak tidak mengalami dismenore sebanyak 33 responden (56,9\%), sedangkan responden dengan tingkat stres sedang lebih banyak mengalami dismenore pada 43 responden (63,0\%). Hasil penelitian didapatkan nilai $\mathrm{p}$ value 0,001, maka dapat ditarik kesimpulan bahwa terdapat hubungan tingkat stress dengan kejadian dismenore pada remaja di MTs Assalafi Susukan.

Penelitian yang dilakukan oleh Berlianawati (2016) diperoleh hasil terdapat hubungan bermakna antara tingkat stres dengan dismenore pada siswi kelas 3 SMK Batik 1 Surakarta dengan p-value 0,001 .

Hasil ini juga didukung oleh penelitian yang dilakukan oleh Diana Sari (2015) yang berjudul Hubungan Stres dengan Kejadian Dismenore Primer pada Mahasiswi Pendidikan Dokter Fakultas Kedokteran Universitas Andalas, dari 165 responden yang mengalami dismenore primer lebih banyak terjadi pada responden yang mengalami stres dengan persentase sebanyak $94 \%$. Stres merupakan salah satu faktor pemicu terjadinya dismenore, stres yang tinggi meningkatkan risiko dismenore.

Dari hasil uji ini juga diperoleh nilai Odds Ratio sebesar 0,123 . Ini menunjukkan bahwa siswi yang mengalami stress sedang beresiko 0,123 kali lebih besar mengalami kejadian dismenore dibandingkan siswi yang mengalami stres ringan.

Tabel 8. Hubungan Konsumsi Cepat Saji dengan Kejadian Dismenore

\begin{tabular}{|c|c|c|c|c|c|c|c|}
\hline \multirow{3}{*}{$\begin{array}{c}\text { Ko } \\
\text { nsu } \\
\text { msi } \\
\text { Fas } \\
t \\
\text { Foo } \\
\quad d\end{array}$} & \multicolumn{4}{|c|}{$\begin{array}{c}\text { Kejadian } \\
\text { Dismenore }\end{array}$} & \multirow{2}{*}{\multicolumn{2}{|c|}{ Total }} & \multirow{3}{*}{$\begin{array}{c}p- \\
v a \\
l u \\
e\end{array}$} \\
\hline & \multicolumn{2}{|c|}{$\begin{array}{l}\text { Dism } \\
\text { enore }\end{array}$} & \multicolumn{2}{|c|}{$\begin{array}{l}\text { Tidak } \\
\text { Dism } \\
\text { enore }\end{array}$} & & & \\
\hline & $\mathbf{n}$ & $\%$ & $\mathrm{n}$ & $\%$ & $\mathbf{N}$ & $\%$ & \\
\hline Jara & 1 & 2 & 2 & 6 & 3 & 1 & 0 \\
\hline ng & 0 & $\begin{array}{l}4 \\
0\end{array}$ & 2 & $\begin{array}{l}8 \\
8\end{array}$ & 2 & $\begin{array}{l}0 \\
0\end{array}$ & $\begin{array}{l}0 \\
0 \\
1\end{array}$ \\
\hline Seri & 7 & 9 & 5 & 6 & 7 & 1 & \\
\hline ng & 1 & 3 & & 2 & 6 & $\begin{array}{l}0 \\
0\end{array}$ & \\
\hline $\begin{array}{l}\text { Tota } \\
1\end{array}$ & $\begin{array}{l}8 \\
1\end{array}$ & $\begin{array}{l}75 \\
, 0\end{array}$ & $\begin{array}{l}2 \\
7\end{array}$ & $\begin{array}{l}2 \\
5, \\
0\end{array}$ & $\begin{array}{l}1 \\
0 \\
8\end{array}$ & $\begin{array}{l}1 \\
0 \\
0\end{array}$ & \\
\hline
\end{tabular}

Hasil tabulasi silang sebagaimana ditunjukkan pada tabel 8 ditemukan bahwa responden yang sering mengkonsumsi cepat saji sebagian besar mengalami dimenore sejumlah 71 responden $(75,0 \%)$. Sedangkan responden yang jarang mengkonsumsi cepat saji sebagian besar tidak mengalami kejadian dismenore sejumlah 22 responden 
$(68,8 \%)$.

Hasil uji Chi Square (Continuity Correction) diperoleh bahwa p-value 0,001 . Oleh karena pvalue $<\alpha(0,05)$, maka disimpulkan bahwa ada hubungan secara signifikan antara konsumsi cepat saji dengan kejadian dismenore pada remaja di MTs Assalafi Susukan.

Hasil uji ini juga diperoleh nilai Odds Ratio sebesar 0,032. Ini menunjukkan bahwa responden yang sering baik mengkonsumsi makanan cepat saji beresiko 0,032 kali besar mengalami kejadian dismenore dibandingkan responden jarang mengkonsumsi makanan cepat saji. Fast food lebih banyak mengandung asam lemak trans yang merupakan salah satu radikal bebas. Salah satu efek dari terpaparnya radikal bebas ini adalah terjadinya kerusakan membrane sel. .

Dalam penelitian Indahwati, Muftiana, \& Purwaningroom (2017), di SMP N 1 Ponorogo terkait hubungan konsumsi fast food dengan dismenore hasil penelitian menunjukkan bahwa (42.9\%) / 27 responden sering mengonsumsi fast food dan mengalami dismenore. Hasil penelitian tersebut menunjukkan ada hubungan mengonsumsi makanan cepat saji (fast food) dengan kejadian dismenore.

Tabel 9. Kebiasaan Olehraga, Tingkat Stres dan Konsumsi Fast Food dengan Kejadian Dismenore

\begin{tabular}{lccc}
\hline Variabel & $\begin{array}{c}\text { OR } \\
\text { (exp.B } \\
\text { ) }\end{array}$ & $\begin{array}{c}\mathbf{9 5 \%} \\
\text { CI }\end{array}$ & $\begin{array}{c}\boldsymbol{p} \text { - } \\
\text { valu } \\
\boldsymbol{e}\end{array}$ \\
\hline Kebiasaa & 0,400 & 0,109 & 0,16 \\
n & & - & 8 \\
Olahraga & & 1,473 & \\
Tingkat & 2,970 & 0,913 & 0,07 \\
Stress & & - & 0 \\
& & 9,658 &
\end{tabular}

$\begin{array}{lccc}\text { Konsums } & 5,615 & 2,161 & 0,00 \\ \text { i Fast } & & - & 1 \\ \text { Food } & & 14,58 & \\ & & 6 & \end{array}$

Kebiasaan olahraga dengan kejadian dismenore mempunyai hubungan tidak bermakna karena hasil uji statistic diperoleh p-value 0,168 , diperoleh pula nilai odd ratio (OR) sebesar 0,400 dan CI (confidence interval) $95 \%$ yaitu antara 0,109-1,473 begitu pula tingkat stres dengan kejadian dismenore mempunyai hubungan tidak bermakna karena hasil uji statistic diperoleh $\mathrm{p}$ - value 0,070 , diperoleh pula nilai odd ratio (OR) sebesar 2,970 dan CI (confidence interval) 95\% antara 0,913-9,658.

Konsumsi makanan cepat saji berhubungan secara bermakna dengan kejadian dismenore karena hasil uji statistic diperoleh p-value 0,001 , diperoleh pula nilai odd ratio (OR) sebesar 5,615 dan CI (confidence interval) $95 \%$ antara 2,161-14,586.

Hal ini sejalan dengan hasil penelitian Pramanik \& Dhar (2014) dengan judul Impact Of Fast Foods On Menstrual Health Of School Going Adolescent Girls In West Bengal Eastern India, didapatkan hasil penelitian bahwa terdapat hubungan yang signifikan antara frekuensi konsumsi fast food dengan abnormalitas menstruasi dan dismenore.

Makanan saji memiliki kandungan gizi yang tidak seimbang yaitu kalori tinggi, tinggi lemak, tinggi gula, dan rendah serat. Kandungan asam lemak didalam makanan cepat saji mengganggu metabolisme progesterone pada fase luteal dari siklus menstruasi. Akibatnya terjadi peningkatan kadar prostaglandin yang akan 
menyebabkan rasa nyeri dismenore.

Pada Penelitian ini terjadinya

dismenore dominan karena dipengaruhi oleh faktor fast food . Fast food mengandung asam lemak trans yang merupakan salah satu radikal bebas. Salah satu efek dari radikal bebas kerusakan membrane sel. Membran sel memiliki beberapa komponen, salah satunya adalah fosfolipid. Salah satu fungsi fosfolipid adalah sebagai penyedia asam arakidonat yang akan disintesis menjadi prostaglandin (Satyanarayana, 2014). Prostaglandin berfungsi membantu rahim berkontraksi dan mengeluarkan lapisan rahim selama periode menstruasi. Jadi, terjadinya penumpukan prostaglandin dalam jumlah yang terlalu banyak tersebutakan menyebabkan terjadinya dismenore.

\section{SIMPULAN}

Sebagian besar responden dalam rentang usia 13-17 tahun $(90,7 \%)$. Kebiasaan olahraga responden sebagian besar memiliki kebiasaan olahraga rutin yaitu sejumlah 56 responden (51,9\%). Tingkat stres responden sebagaian besar mengalami tingkat stres berat yaitu sejumlah 58 responden $(53,7 \%)$. Konsumsi makanan cepat saji responden sebagian besar memiliki kebiasaan makanan cepat saji yang jarang yaitu sejumlah 63 responden $(58,3 \%)$. Kejadian dismenore responden sebagian besar mengalami dismenore yaitu sejumlah 68 responden $(63,0 \%)$. Ada hubungan kebiasaan olahraga dengan kejadian dismenore pada remaja dengan $\mathrm{p}$ value 0,001 .

Ada hubungan tingkat stres dengan kejadian dismenore pada remaja dengan p-value 0,001. Ada hubungan konsumsi fast food dengan kejadian dismenore pada remaja dengan p-value 0,001. Faktor yang paling dominan berhubungan dengan terjadinya dismenore adalah konsumsi makanan fast food dengan OR 5,878. Hasil penelitian ini dapat dijadikan sebagai bahan masukan bagi UKS sebagai acuan dalam memberikan pelayanan kesehatan pada remaja dengan memberikan pendidikan kesehatan pentingnya melakukan olahraga secara rutin, manajemen stres serta mengurangi konsumsi fast food sebagai upaya pencegahan dismenore.

\section{DAFTAR PUSTAKA}

Astuti, N.D. (2014) Hubungan Frekuensi Konsumsi Fast Food Dan Status Gizi Dengan Usia Menarche Dini Pada Siswi Sekolah Dasar Di Surakarta. Skripsi. Universitas Muhammadiyah Surakarta. http://eprints.ums.ac.id/32297 I

Bahri, A.N, Afriwardi, Yusrawati ( 2015).Hubungan antara Kebiasaan Olahraga dengan Dismenore pada Mahasiswi Pre-Klinik Program Studi Pendidikan Dokter Fakultas Kedokteran Universitas Andalas Tahun Ajaran 20122013.http://jurnal.fk.unand.ac .id/index.php/jka/article/view/ 369

Berlianawati,N.A. Hubungan antara Tingkat Stres dengan Dismenore pada Siswi Kelas Tiga SMK Batik Surakarta. http://eprints.ums.ac.id/41176 /1/naskah\%20publikasi.pdf 
Eastern India. Global Institute of Research \& Education, vol. 3(1), pp. 61-66, 2014

El Manan, 2013. Kamus Cerdik kesehatan Wanita. Yogyakarta : Flash Book

Fajaryati,N.(2012). Hubungan Kebiasaan Olahraga Dengan Dismenore Primer Remaja Putri Di Smp N 2 Mirit Kebumen. Jurnal Komunikasi Kesehatan, 3, 2-3.

Retrieved from http://e- journal.akbid purworejo.ac.id/index.php/jkk 4/arti cle/view/62

Husnida,N. dan Sutianingsih,H. (2015). Hubungan antara Status Gizi dan Oleh Raga dengan Kejadian Dismenore pada Mahasiswi Jurusan Kebidanan Rangkasbitung Tahun 2015. Jurnal Medikes Vol. 2 No 2 Tahun 2015. https://jurnal.poltekkesbanten .ac.id/Medikes/issue/view/4

Indahwati, A. N., Muftiana, E., \& Purwaningroom, D. L. (2017). HubunganMengonsumsi Makanan Cepat Saji (Fast Food) dengan Kejadian Dismenore Pada Remaja Putri di SMP N 1 Ponorogo. Indonesian Journal for Health Sciences, 1(2), 7-13.

Indahwati, A. N., Muftiana, E., \& Purwaningroom, D. L. (2017). Hubungan Mengonsumsi Makanan Cepat Saji (Fast Food) dengan Kejadian Dismenore Pada Remaja Putri di SMP N 1 Ponorogo.
Indonesian Journal for Health Sciences, 1(2), 7-13. https://doi.org/10.24269/ijhs. v1i2.2017.4, Diakes tanggal 22 Juni 2019.

Meilina. Saputri (2011) Karya Tulis Ilmiah Hubungan Antara Stres Dengan Kejadian Dismenorea Pada Siswi SMK N 1 Karanganyar http://eprints.uns.ac.id diakses tanggal 27 Februari 2019

Owusu \& Apenten (2019). Introduction to Food Chemistry. $1^{\text {st }}$. CRC Press.

Pramanik ,P. \& Dhar, A. (2014).Impact Of Fast Foods On Menstrual Health Of School Going Adolescent Girls In West Bengal Eastern India. Global Institute for Researce and Education.Vol 3 (1):61-66

Pundati,T.M. Sistiarani,C. dan Hariyadi,B. (2016). Faktorfaktor yang Berhubungan dengan Kejadian Dismenore pada Mahasiswa Semester VIII Universitas Jendral Sudirman Purwokerto. Jurnal Kesmas Indonesia, Volume 8 No 1, Januari 2016, Hal 40-48 Retrieved from http://jos.unsoed.ac.id/index.p $\mathrm{hp} /$ kesmasindo/article/view/1 40/129

Saguni.F.C.A, Madianung.A, Masi.G. (2013). Hubungan dismenore dengan aktivitas belajar remaja putri di SMA Kristen I Tomohon. Ejournal keperawatan (e-Kp) ;Vol 1.No 1 
Sari, D. (2015). Hubungan Stres dengan Kejadian Dismenore Primer Pada Mahasiswa Pendidikan Dokter Fakultas Kedokteran Universitas Andalas. Jurnal Kesehatan Andalas. Diunduh Tanggal 20 Oktober 2019

Satyanarayana,U. ( 2014), Bibliographic \& Subject Control,Pre-clinical

Medicine: Basic Sciences, Biochemistry, Materials Science 4th edition, Made Simple

Sirait,Deby Shinta O. (2014). Faktor - Faktor yang berhubungan dengan Kejadian Dismenore pada Siswi SMA Negeri 2 Medan.

http://repository.usu.ac.id/bit stream/handle/123456789/48 919/Cover.pdf?sequence $=7 \&$ isAllowed $=\mathrm{y}$

Sophia, Frenita, dkk(2013).Faktor faktor yang berhubungan dengan dismenore Pada siswi smk negeri 10 medan Tahun 2013 (Diunduh tanggal 15 April 2019). Diakses di: http://jurnal.usu.ac.id/index.p hp/gkre/article/view/4060 